\title{
ANALISIS KEPUASAN WISATAWAN TERHADAP VARIASI PAKET DENPASAR CITY TOUR
}

\author{
Shintia Jayanti \\ I Wayan Suardana \\ I Made Kusuma Negara \\ Email : shintialee@gmail.com \\ PS. S1 Industri Perjalanan Wisata \\ Fakultas Pariwisata UNUD
}

\begin{abstract}
Denpasar city tour as one of tourism product in Bali, also developed becomes one of favorite choice for tourist. Since tourism industry product is very dynamic and depends on the environment, it is important to know tourist's perception and analysis about tourist satisfaction for variety of Denpasar city tour, for making some regulation to improve the product or making some innovation about the product. This research conducted by questionnaire method, also supported with interviews and direct observation. The results analyzed by using Importance-Performance Analysis. The result showed that tourist felt dissatisfaction about the product (Denpasar city tour) as shown at the indicator (92,75 percent), and cartecius diagram showed that there are some point that is important for the tourist and should be maintain the performance, such as variation object, facility in the object, reliable information. There are also some point that tourist feel it is important but they feel dissatisfaction about it. There are security checks and security staffs in the object.
\end{abstract}

Keywords: Denpasar City Tour, Dissatisfaction, Satisfaction Analysis.

\section{PENDAHULUAN}

Bali merupakan jendela dunia dalam melihat Indonesia dan juga sebagai pusat pengembangan kepariwisataan Indonesia. Perkembangan pariwisata Bali sejak tahun 2000 cenderung mengalami kenaikan. Denpasar yang merupakan pusat pemerintahan, pusat perdagangan, pusat pendidikan, dan pusat industri di Bali yang memiliki 4 Kecamatan, yaitu Kecamatan Denpasar Barat, Denpasar Timur, Denpasar Selatan dan Denpasar Utara.

Program sightseeing Denpasar pada umumnya dikemas oleh Biro Perjalanan Wisata sebagai Denpasar City Tour, dimana yang menjadi destinasi wisata tentu merupakan potensi yang dimiliki oleh kota denpasar. Namun, saat ini masih banyak potensi yang belum dikembangkan atau diakses oleh BPW sebagai bagian dari city tour yang ditawarkan. Selain itu pengembangan city tour juga dirasakan kurang adanya komitmen pemerintah untuk mengimplementasikan secara konsisten dan berkelanjutan. Sehingga untuk dapat mengembangkan Denpasar dalam paket city tour, maka perlu adanya penelitian lebih mendalam agar dapat mengetahui faktor yang perlu ditingkatkan dan juga inovasi-inovasi yang perlu dilakukan, mengingat industri pariwisata merupakan industri yang sangat dinamis dan sangat mudah terpengaruh oleh perubahan yang terjadi. Berdasarkan latar belakang tersebut, maka tujuan penelitian ini adalah untuk mengetahui bagaimana kepuasan wisatawan terhadap variasi paket Denpasar City Tour.

\section{METODE PENELITIAN}

Variabel yang digunakan dalam penelitian ini, untuk membatasi ruang lingkup permasalahan yang diteliti, adalah :

1. Persepsi Wisatawan, variabel dalam persepsi yang akan dinilai adalah bukti 
langsung, keandalan, daya tanggap , jaminan, dan empati.

2. Kepuasan wisatawan merupakan perbandingan antara: harapan (expectation), kinerja (performance), dan derajat kepentingan (importance).

Metode yang digunakan untuk menentukan jumlah sampel, yang dalam hal ini adalah wisatawan yang menikmati Denpasar city tour, menggunakan model J. Supranto, dengan jumlah responden sebanyak 65 orang berdasarkan hasil dari perkalian 5 dengan 13 pertanyaan (indikator) dalam kuesioner, sedangkan untuk memenuhi responden yang dibutuhkan menggunakan accidental sampling atau cara pengambilan sampel secara kebetulan.

Teknik analisis data yang digunakan dalam penelitian ini adalah analisis kuantitatif, dimana penelitian ini menggunakan metode analisis Importance-Performance Analysis dengan menggunakan skala Likert. Sesuai dengan kategori skor yang diberikan yaitu satu untuk skor terendah dan lima untuk skor terbesar. Berdasarkan hasil penelitian kepentingan dan hasil penilaian kinerja atau kualitas produk yang dirasakan, maka akan dihasilkan suatu perhitungan mengenai tingkat kesesuaian antara tingkat kepentingan dan tingkat kualitas kinerja atau produk yang dirasakan. Tingkat kesesuaian adalah hasil perbandingan dari skor kinerja dan skor kepentingan, jika tingkat kesesuaian responden sama dengan 100 persen maka wisatawan merasa puas, sedangkan jika hasil perbandingan skor tersebut dibawah 100 maka wisatawan merasa tidak puas. Hasil perbandingan skor tersebut juga kemudian digambarkan dalam diagram Cartesius. Dalam diagram Cartesius, posisi masing-masing indikator dapat diketahui berdasarkan rata-rata total skor yang didapat atas kinerja dan juga kepentingan menurut wisatawan.

\section{PEMBAHASAN}

\section{Karakteristik Wisatawan}

Karakteristik wisatawan yang melakukan atau menikmati Denpasar City Tour berdasarkan kuesioner yang telah disebarkan kepada 65 orang wisatawan yaitu peminat Denpasar City Tour didominasi oleh perempuan dengan jumlah 37 orang, wisatawan dengan umur 20 sampai dengan 30 tahun, warga negara Indonesia sebanyak 57 orang, wisatawan yang pertama kali berkunjung sebanyak 56 orang, dan didominasi oleh penyusunan pribadi/teman sebanyak 42 orang.

\section{Analisis Tingkat Kepentingan dan Kinerja Wisatawan Terhadap Denpasar City Tour}

Hasil analisis tingkat kesesuaian responden, skor rata-rata penilaian tingkat kinerja dan skor penilaian kepentingan. Berdasarkan tabel tersebut dapat diketahui bahwa responden merasa tidak puas dengan variasi paket Denpasar city tour, dengan total skor tingkat kesesuaian sebesar 92,75 persen atau kurang dari 100 persen.

\section{Analisis Indikator Produk pada Diagram Cartesius}

Letak indikator-indikator dalam diagram cartesius yang dihasilkan dapat dijelaskan sebagai berikut.

1. Kuadran A (indikator yang penting, namun kinerja tidak memuaskan), yaitu: Adanya pemeriksaan keamanan yang dilakukan saat mengunjungi obyek wisata kota(10), ketersedian staff keamanan di obyek wisata kota yang dikunjungi(11).

2. Kuadran B (indikator yang penting dan kinerja telah sesuai dengan yang diharapkan), yaitu:Variasi perpaduan obyek wisata kota dalam suatu rencana perjalanan atau itinerary (1), Fasilitas yang ada di setiap obyek wisata kota (2), Informasi dan pengalaman yang di dapat (3), Obyek wisata kota antara yang satu dengan yang lain tidak monoton dalam suatu rencana perjalanan (6), Kesesuaian obyek wisata kota dengan informasi mengenainya yang di dapat (7), Interaksi tambahan yang diadakan oleh obyek wisata kota (9).

3. Kuadran $\mathrm{C}$ (indikator yang kurang penting dan kinerjanya biasa saja), yaitu: Tersedianya guide lokal di obyek wisata kota (4), Pemberian informasi secara benar oleh guide atau staff (5), Pemberian salam oleh staff ketika mengunjungi obyek wisata kota (12), Pemberian perhatian atas kebutuhan wisatawan oleh staff dan guide (13).

4. Kuadran D (indikator dinilai kurang penting namun pelaksanaannya 
berlebihan), yaitu: Guide atau staff selalu memberikan informasi dengan ramah dan sopan (8).

\section{SIMPULAN DAN SARAN}

\section{Simpulan}

1. Sesuai dengan tingkat kesesuaiaan antara rata-rata skor dari tingkat kinerja dengan rata-rata dari skor tingkat kepentingan maka dapat disimpulkan bahwa wisatawan merasa tidak puas dengan kinerja produk yang diterima karena tingkat kesesuaiaan sebesar 92,75 persen.

2. Berdasarkan hasil diagram cartesius maka diperoleh indikator-indikator yang dinilai perlu mendapatkan prioritas dalam pelaksanaannya karena keberadaannya dianggap penting oleh wisatawan, sedangkan kinerja atau pelaksanaannya masih belum dapat memuaskan, antara lain adanya pemeriksaan keamanan yang dilakukan saat mengunjungi obyek wisata kota (10) dan ketersedian staff keamanan di obyek wisata kota yang dikunjungi (11).

\section{Saran}

Beberapa saran yang sekiranya dapat manjadi masukan antara lain perlunya diadakan staff keamanan di setiap obyek wisata kota, perlunya variasi dalam penyusunan suatu paket oleh BPW, dan inovasi produk dengan mengikutsertakan wisatawan dalam kegiatan. Hendaknya pemerintah menyediakan papan peta obyek wisata kota di setiap obyek wisata kota sehingga wisatawan yang mengatur perjalanannya sendiri dapat menentukan tujuan berikutnya dengan mudah.

\section{DAFTAR PUSTAKA}

Desky, M.A. 2001. Pengantar Bisnis Biro Perjalanan Wisata. Yogya: AdiCita

Dinas Pariwisata kota Denpasar. 2012. Data Pariwisata Kota Denpasar 2011.

Kusmayadi. 2002. Metodologi Penelitian dalam Bidang Kepariwisataan. Jakarta: PT. Gramedia Pustaka Utama.

Putra, Asmara. 2007. Denpasar "City Tour", Komitmen Setengah Hati. http://www.balipost.co.id/BaliPostcetak/ 2007/4/12/pa3.htm diakses 12 April 2012 pukul 5.12 PM

Usman, Husaini dan Purnomo Setiady. 2004. Metodologi Penelitian Sosial. Jakarta: PT Bumi Aksara

Wardiyanta. 2006. Metodologi Penelitian Pariwisata. Yogya: CV Andi Offset.

Yoeti, Oka. A. 2006. Tours and Travel Management. Jakarta: PT. Pradnya Paramita. 